\title{
Penggunaan Teknologi Tepat Guna Meja Colet Batik di Rumah Kreatif De Suket
}

\author{
Amalia $^{1}$, Rudy Tjahyono ${ }^{2}$ \\ 1,2 Program Studi Teknik Industri, Universitas Dian Nuswantoro \\ E-mail: ${ }^{1}$ amalia@dsn.dinus.ac.id, ${ }^{2}$ rudi.tjahyono@dsn.dinus.ac.id
}

\begin{abstract}
Abstrak
Sebagian besar industri batik di Indonesia termasuk ke dalam unit usaha kecil dan menengah (UKM), sehingga membutuhkan peningkatan daya saing UKM melalui pengembangan alat bantu untuk mempermudah proses pembuatan batik. Salah satu proses pembuatan batik yang paling penting adalah pewarnaan. Pewarnaan dengan teknik colet merupakan salah satu teknik praktis, efisien dan memberikan daya tarik bagi produk Batik. Rumah Kreatif De Suket memiliki permasalahan dalam menjalankan usahanya, antara lain keterbatasan alat dalam proses pencoletan dan luas ruang yang sempit. Proses pencoletan dilakukan menggunakan gawangan batik atau terkadang hanya alakadarnya di lantai. Hal ini dapat menghambat produktivitas, serta postur atau posisi kerja yang salah dapat mengakibatkan cidera atau penyakit kerja. Rumah kreatif juga memiliki luas ruang yang sempit sehingga sulit menyimpan peralatan kerja, seperti meja colet yang tersedia di pasaran. Program kemitraan masyarakat ini bertujuan untuk menyelesaikan permasalahan yang dihadapi mitra antara lain mempermudah proses produksi terutama pada bagian pewarnaan dengan teknik colet, memiliki postur kerja yang baik, dan memudahkan penyimpanan pada stasiun kerja pencoletan.
\end{abstract}

Kata kunci: teknologi tepat guna, pencoletan, batik

\begin{abstract}
Most of Batik industry in Indonesia belongs to small and medium enterprises (SMEs). It requires to increase the competitiveness of SMEs through the development of tools to facilitate the batik process. One of important batik process is coloring. Colet or Coletan is an easy, practical and efficient coloring technique. This technique can provide value added in the form of attractiveness to batik products. Rumah Kreatif De Suket has issues regarding tools availability especially in Colet process, and also related to narrow workspace. Coloring process with colet technique is carried out using gawangan or manually in floor. Incorrect work posture or position can lead to work injury or occupational diseases. RK De Suket also have a limited work area where work equipment or tools become difficult to store, such as colet table currently available in the market. Community partnership program aims to solve the problems faced by partners, among others, simplifying the production process, especially in the coloring section with colet technique, having a correct working posture, and facilitating storage at the colet workstation.
\end{abstract}

Keywords: Appropriate technologi, colet technique, batik

\section{PENDAHULUAN}

Batik merupakan identitas budaya Indonesia dimana warga masyarakat Indonesia mengenakan baju batik karena warisan leluhur bangsa Indonesia, serta batik memiliki kekhasan maupun keunikan yang membedakan bangsa Indonesia dengan bangsa lain [1]. Sebagian besar industri batik di Indonesia termasuk ke dalam unit usaha kecil dan menengah (UKM), sehingga membutuhkan kebijakan-kebijakan dari pemerintah agar tidak terlindas dari industri-industri besar yang memiliki modal besar [3]. Tidak hanya modal, sarana prasarana yang tersedia di 
industri besar juga lebih lengkap, tentu saja dapat menjadi ancaman bagi UKM yang merupakan mata pencaharian sebagian masyarakat. Oleh karena itu, untuk meningkatkan daya saing UKM perlu dilakukan peningkatan produktivitas UKM secara efektif dan efisien, salah satunya dengan mengembangkan alat bantu yang dapat mempermudah dan mempercepat proses produksi batik. Perancangan alat bantu dapat mempermudah proses pembuatan batik [4].

Diketahui bahwa untuk menghasilkan batik, terdapat berbagai proses yang panjang, yaitu dimulai dari pembuatan desain, proses pembatikan, pewarnaan, pelorodan, penjemuran hingga menjadi kain batik yang berwujud kain panjang, maupun produk baju, dan lain-lain. Salah satu proses yang penting yaitu pewarnaan. Teknik pewarnaan batik dapat dilakukan dengan pencelupan, pencoletan, maupun perkembangan teknik-teknik lainnya. Menurut Lestari [2], teknik pewarnaan colet disebut sebagai teknik yang cukup praktis dan efisien dalam menghemat zat warna dibanding teknik celup.

Sasaran dalam kegiatan pengabdian masyarakat ini adalah Rumah Kreatif De Suket. Rumah Kreatif De Suket merupakan Usaha Mikro Kecil dan Menengah (UMKM) yang bergerak dalam bidang edukasi dan pelatihan, serta produksi dari produk-produk kreatif, ternasuk Batik. Rumah Kreatif De Suket merupakan usaha yang baru saja berdiri di tahun 2019 yang memiliki tujuan memberikan ruang bagi inovasi, sharing informasi, serta keterampilan dan motivasi bagi masyarakat yang ingin mengembangkan diri dan berwirausaha. Rumah Kreatif de Suket memiliki visi menjadi Lembaga Pengembang Masyarakat Kreatif, Inovatif, dan Produktif. Rumah Kreatif ini dibangun dengan harapan dapat mendorong pertumbuhan dan perkembangan ekonomi kreatif dalam masyarakat terutama dalam bidang kerajinan Batik dan tekstil. Akan tetapi, dalam menjalankan usahanya, masih banyak terdapat kekurangan, salah satunya ketidaklengkapan sarana alat yang dimiliki untuk menunjang kegiatan produksi maupun pelatihan. Tidak hanya itu, tempat usaha rumah kreatif ini memiliki luas ruang yang terbatas.

Secara umum, keterbatasan alat dan ruang yang dimiliki Rumah kreatif ini menghambat proses produksi maupun kegiatan pelatihan yang dilakukan di rumah kreatif ini. Dalam proses pewarnaan menggunakan teknik colet, rumah kreatif belum memiliki meja colet, sehingga pekerja atau jika ada peserta pelatihan melakukan proses pencoletan dengan gawangan batik atau bahkan alakadarnya dengan duduk di lantai. Hal ini, mendorong akademisi untuk bisa mengatasi problema yang dihadapi dengan pengembangan alat bantu. Suryanto [4] juga memberikan saran yang perlu dipertimbangkan dalam pengembangan perancangan alat bantu yaitu pengembangan alat perlu memperhatikan prinsip-prinsip kerja ergonomi, memperhatikan hal teknis yang dapat berpengaruh terhadap hasil dan tujuan awal perancangan, dan pertimbangan dimensi alat.

Rumah kreatif de Suket memiliki potensi meningkatkan perekonomian nasional yang berbasis ekonomi kreatif dalam subsektor fashion dan kriya. Tidak hanya itu, usaha ini juga memberikan ruang bagi masyarakat yang ingin meningkatkan pengetahuan dan keterampilan dalam bidang kerajinan batik dan tekstil. Rumah kreatif de suket belum memiliki sarana untuk melakukan proses pencoletan, sehingga posisi kerja yang tidak sesuai dengan standar. Apabila posisi / postur kerja kurang baik dapat berdampak buruk bagi kesehatan pekerja maupun peserta pelatihan. Selain itu, pertimbangan lain meja colet yang ada di pasaran memiliki ukuran cukup besar yang menyulitkan dalam penyimpanan, dikarenakan luas ruang yang dimiliki rumah kreatif ini dapat digolongkan sempit.

Berdasarkan analisis situasi dan permasalahan mitra yang telah disampaikan pada subbab diatas, maka inti permasalahan yang dihadapi adalah: "Bagaimana meningkatkan kenyamanan posisi kerja di Rumah Kreatif De Suket khususnya pada proses pencoletan dengan mempertimbangkan keterbatasan luas ruang?" 


\section{METODE}

Pelaksanaan kegiatan "Penggunaan Teknologi Tepat Guna Meja Colet Batik di Rumah Kreatif De Suket" meliputi tiga tahapan utama, yaitu 1. Koordinasi mitra; 2. Pelaksanaan Kemitraan; 3. Evaluasi.

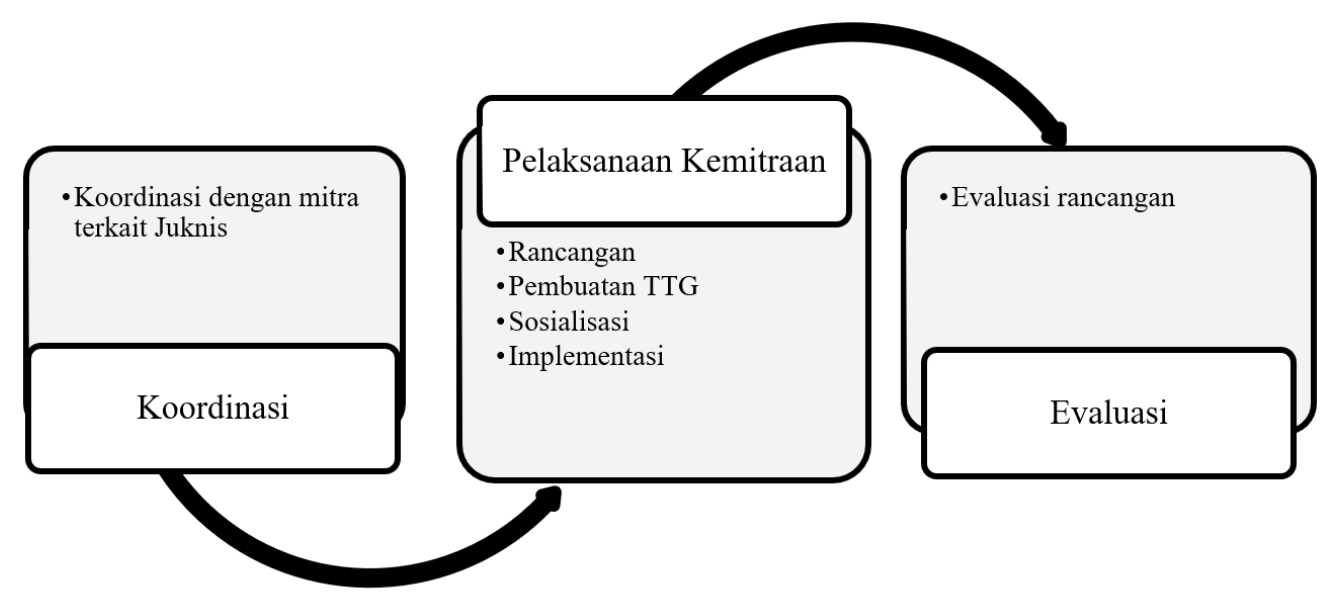

Gambar 1. Tahapan Kegiatan Pengabdian

\subsection{Koordinasi Mitra}

Mitra dalam kegiatan ini adalah Rumah Kreatif (RK) de Suket. Koordinasi ditujukan untuk: a) menganalisis situasi dan kondisi mitra; b) menentukan kebutuhan rancangan teknologi; c) menentukan jadwal pelaksanaan implementasi dan sosialisasi teknologi.

\subsection{Pelaksanaan Kemitraan}

Pelaksanaan kemitraan dilakukan sejak awal koordinasi dimulai, yaitu mengidentifikasi kebutuhan rancangan, selama proses perancangan, pembuatan teknologi tepat guna sesuai kebutuhan mitra, serta kegiatan sosialisasi dan implementasi di lokasi mitra RK De Suket.

\subsection{Evaluasi}

Pada tahapan evaluasi dilakukan dengan menangkap umpan balik dari mitra terkait teknologi yang telah dibuat. Serta dilakukan penyusunan laporan pertanggungjawaban kegiatan.

\section{HASIL DAN PEMBAHASAN}

Koordinasi dengan mitra terkait waktu pelaksanaan kemitraan dan rencana kegiatan yang dimulai dari identifikasi kebutuhan rancangan dan spesifikasi yang rancangan yang dibutuhkan Mitra. Koordinasi ini dilakukan pada awal pelaksanaan kegiatan, berjalan beriringan ketika perancangan, hingga sosialisasi dan evaluasi kegiatan secara bersama-sama. 


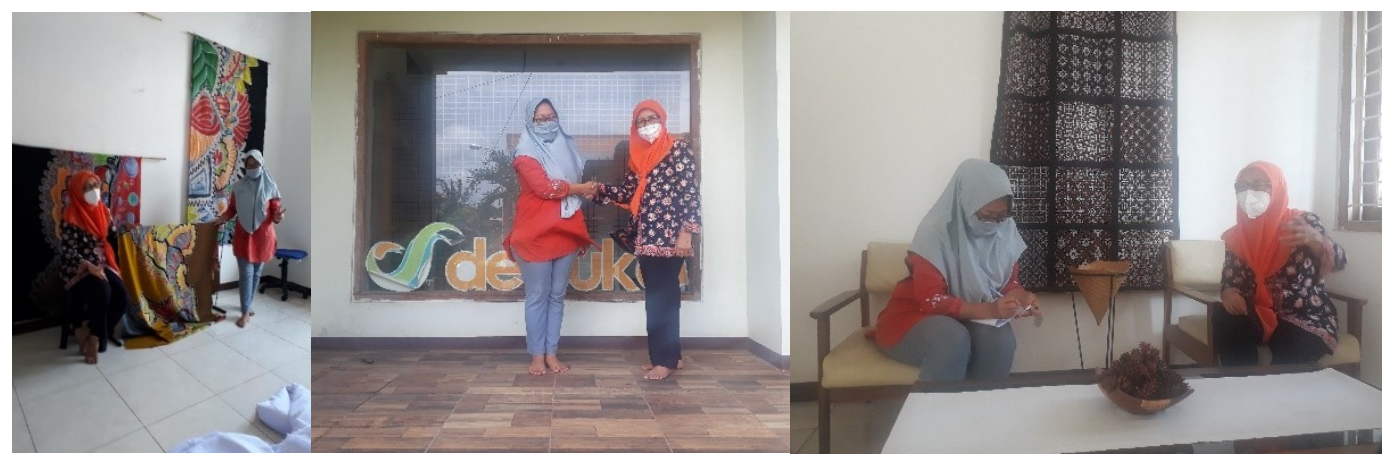

Gambar 2. Kegiatan Koordinasi Mitra

\subsection{Proses Pencoletan di Rumah Kreatif De Suket Awal}

Mitra Rumah Kreatif de Suket belum memiliki meja kerja untuk melakukan proses pencoletan. Proses pencoletan yang dilakukan selama ini menggunakan lantai yang diberikan alas seadanya, terkadang karpet, goni, dan lain sebagainya. Adapun identifikasi awal dilakukan untuk mengukur tingkat resiko postur kerja dengan proses awal yang telah dilakukan Mitra.
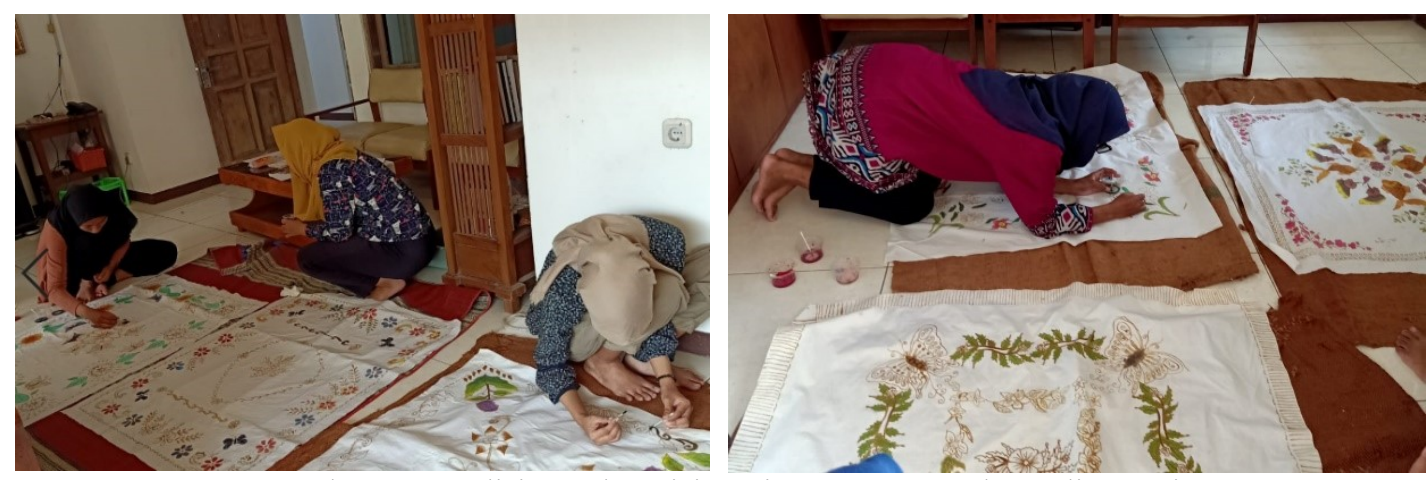

Gambar 3. Kondisi Awal Posisi Kerja Proses Pencoletan di Lantai

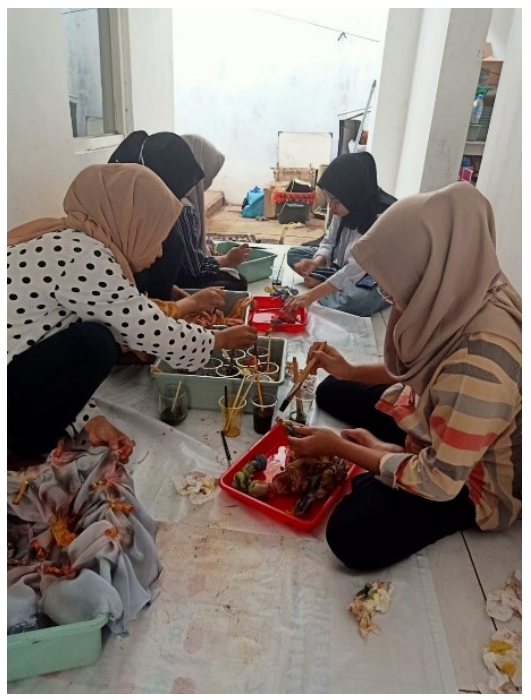

Gambar 4. Kondisi Awal Proses Pencoletan di Ruang Sempit

Mitra RK De Suket belum memiliki pembagian ruang secara khusus, ketersediaan ruang digunakan bergantian dengan proses lainnya seperti pemotongan kain, pembuatan pola, maupun 
pembatikan tulis. Lokasi pencoletan pun bervariasi bisa dilakukan pada ruang tengah, atau di ruang pembahanan, maupun di Lorong.

\subsection{Rancangan Meja Kerja Pencoletan}

Meja kerja pencoletan dirancang untuk pekerja maupun peserta pelatihan dengan posisi kerja berdiri dan duduk. Rancangan ini ditujukan untuk mendapatkan postur pekerja yang lebih baik. Rancangan meja kerja selain mempertimbangkan postur kerja dan dimensi antropometri, juga mempertimbangkan ukuran kain yang biasa diproduksi yaitu panjang kain 2 meter dan lebar kain 1,15-1,2 meter. Pertimbangan lainnya adalah mengenai ruang yang digunakan untuk proses pencoletan digunakan bergantian dengan proses lainnya, maka meja yang dibuat dapat dibongkar pasang sesuai kebutuhan, dan tempat penyimpanan diatur agar tidak memakan ruang.

\subsection{Pembuatan Meja Colet}

Proses pembuatan meja colet memerlukan waktu 2 minggu. Ada pun material yang digunakan adalah besi hollow. Penggunaan material ini diharapkan memberikan kekuatan alat sehingga tidak mudah rusak dalam jangka waktu yang lama.

\subsection{Implementasi dan Sosialisasi Meja Colet}

Meja kerja colet yang telah jadi diimplementasikan secara langsung kepada Mitra. Implementasi ini juga dibarengi dengan kegiatan sosialisasi kepada pemilik dan pengguna / pekerja di bagian pencoletan. Adapun sosialisasi yang dilakukan meliputi 1) Pemasangan meja; 2) Penggunaan meja; 3) Penyimpanan meja. Sosialisasi dilengkapi dengan buku petunjuk penggunaan alat dan juga dipraktikkan secara langsung.

a. Pemasangan Meja

Meja dipasang dengan merakit bagian kaki dan alas frame meja.

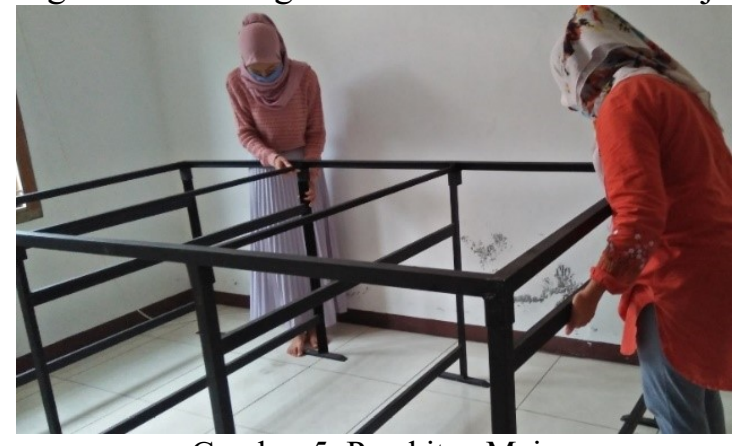

Gambar 5. Perakitan Meja

b. Penggunaan Meja

Penggunaan meja dibuat untuk posisi kerja berdiri dan duduk agar pekerja tidak mudah lelah. 


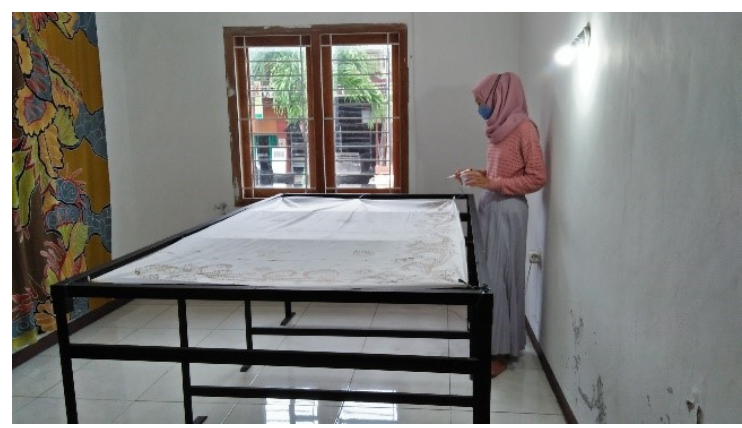

Gambar 6. Penggunaan Meja Colet dengan Posisi Kerja Berdiri

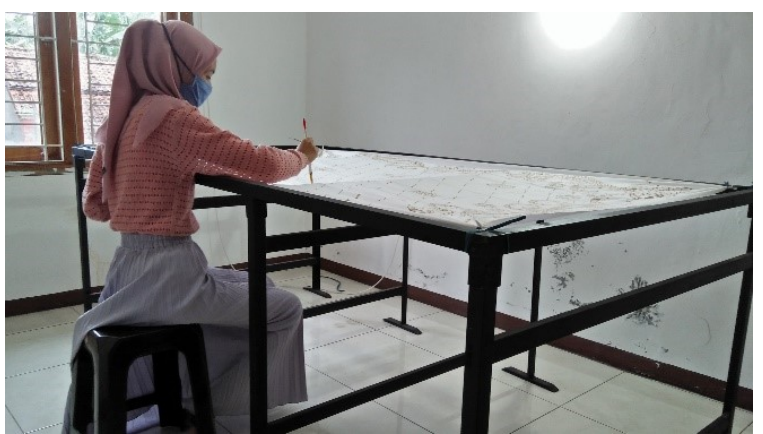

Gambar 7. Penggunaan Meja Colet dengan Posisi Kerja Duduk

c. Penyimpanan Meja

Meja dapat disimpan dengan melepas rakit antara kaki meja dengan alas meja.

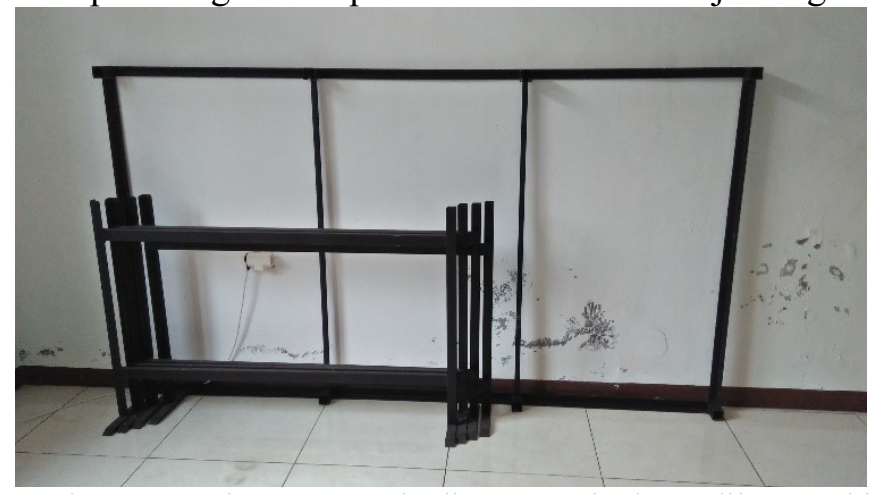

Gambar 8. Penyimpanan Meja dimana Meja dapat dilepas-rakit

\subsection{Tanggapan Mitra}

Pengukuran kepuasan mitra RK De Suket terhadap implementasi teknologi tepat guna meja colet menggunakan indikator kemudahan penggunaan alat, kenyamanan penggunaan alat, kualitas alat, dan rancangan alat hemat ruang. Pengukuran menggunakan skala likert 1 sampai 5, dimana nilai 1 adalah nilai terkecil yang menginterpretasi variabel yang diukur tidak sesuai, hingga nilai terbesar 5 yang menginterpretasikan variabel yang diukur sangat sesuai. Pengukuran interval kriteria penilaian yakni:

Tabel 1. Kriteria Penilaian

\begin{tabular}{|c|c|}
\hline Interval Nilai & Kriteria Penilaian \\
\hline $1,00-1,79$ & Sangat Buruk \\
\hline $1,80-2,59$ & Buruk \\
\hline $2,60-3,39$ & Cukup Baik \\
\hline $3,40-4,19$ & Baik \\
\hline $4,20-5,00$ & Sangat Baik \\
\hline
\end{tabular}


Hasil pengukuran tanggapan mitra RK De Suket berdasarkan kategori kemudahan penggunaan alat, kenyamanan penggunaan alat, kualitas alat, dan rancangan alat hemat ruang ditunjukkan pada Gambar 6.

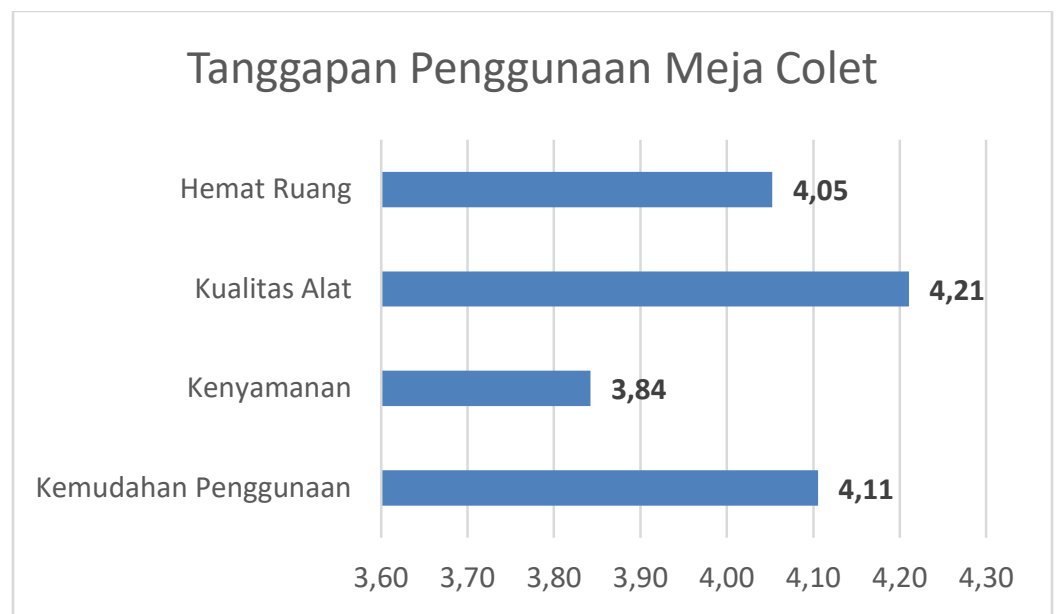

Gambar 9. Tanggapan Penggunaan Teknologi Tepat Guna Meja Colet pada Mitra RK De Suket

Berdasarkan hasil pengukuran tanggapan mitra, dapat disimpulkan bahwa teknologi tepat guna yang telah dibuat memiliki nilai tanggapan yang baik. Berdasarkan hasil kuesioner diperoleh hasil per variable, yakti:

1. Dalam aspek kemudahan penggunaan alat dihasilkan nilai sebesar 4,11, yakni berada pada interval Baik (B). Hal ini menunjukkan bahwa teknologi meja colet yang dibuat sudah memiliki nilai kemudahan yang baik, karena meja ini membantu dan bermanfaat dalam proses pewarnaan dengan teknik colet agar lebh efektif, produktif.

2. kenyamanan penggunaan alat dihasilkan nilai sebesar 3,84 yakni berada pada interval Baik (B). Hal ini menunjukkan bahwa teknologi meja colet yang dibuat dirasa nyaman ketika digunakan, baik oleh pekerja, maupun peserta pelatihan

3. kualitas alat dihasilkan nilai sebesar 4,21 yakni berada pada interval Sangat Baik (SB). Hal ini menunjukkan bahwa teknologi meja colet yang dibuat terjamin kekuatannya, dan baik untuk digunakan

4. rancangan alat hemat ruang dihasilkan nilai sebesar 4,05 yakni berada pada interval Baik (B). Hal ini menunjukkan bahwa teknologi meja colet yang dibuat sudah memiliki kriteria hemat ruang, terutama dalam hal penyimpanan alat karena dibuat dalam bentuk knock-down yang mudah untuk dilepas rakit ataupun sebaliknya.

\section{KESIMPULAN DAN SARAN}

Kesimpulan yang diperoleh adalah kegiatan pengabdian masyarakat dengan pembuatan rancang-bangun teknologi tepat guna ini dapat membantu proses pekerjaan pewarnaan dengan teknik colet pada mitra RK De Suket, serta dapat meningkatkan kenyamanan dalam bekerja baik dalam posisi berdiri dan duduk yang dapat menurunkan resiko cidera otot, serta meja ini dapat digunakan meski lahan ruang terbatas. Tanggapan mitra menunjukkan bahwa teknologi tepat guna yang dirancang mampu memberikan kemudahan dalam penggunaan $(4,11)$, kenyamanan digunakan $(3,84)$, kualitas alat yang baik $(4,21)$, dan alat hemat ruang $(4,05)$.

Saran dalam kegiatan ini adalah dapat dilakukan perbaikan rancangan khususnya pada 
bagian penjepit kain dan penghubung tengah, agar kain dapat meregang dengan lebih baik. Perlu pula dibuat inovasi untuk proses-proses lainnya agar produktivitas dapat ditingkatkan.

\section{UCAPAN TERIMA KASIH}

Penulis mengucapkan terima kasih kepada Lembaga Penelitian dan Pengabdian kepada Masyarakat (LPPM) Universitas Dian Nuswantoro atas pendanaan pada skema Pengabdian Kepada Masyarakat (001/A.38-04/UDN-09/I/2021). Penulis juga berterima kasih kepada mitra, dan berbagai pihak.

\section{DAFTAR PUSTAKA}

[1] Iskandar, E. Kustiyah, 2017, Batik sebagai Identitas Kultural Bangsa Indonesia di Era Globalisasi, GEMA Thn XXX/52 pp.2456-2472, ISSN 0215-3092.

[2] Lestari, Ika, 2018, Perbedaan Hasil Pewarnaan Teknik Colet dan Semprot untuk Batik Kontemporer, Skripsi Universitas Negeri Semarang.

[3] Nurainun, Heriyana, dan Rasyimah, 2008, Analisis Industri Batik di Indonesia, Fokus Ekonomi Vol. 7 No. 3, Desember 2008, pp. 124-135, ISSN: 1412-3851.

[4] Suryanto, S.M., M. Chaeron, T. Wibawa, 2016, Perancangan Alat Bantu Proses Pembuatan Batik Sarita, Jurnal OPSI Vol. 9 No. 2 Desember 2016, ISSN 1693-2102. 